\title{
MECHANISMS OF COMMON GROUND IN CASE-BASED WEB-DISCUSSIONS IN TEACHER EDUCATION
}

This is a post-print of an article submitted for consideration in the Internet and Higher Education (C) 2002 Elsevier.

Personal use of this manuscript is permitted. Permission from Elsevier must be obtained for any other commercial purpose.

This article may not exactly replicate the published version, due to editorial changes and/or formatting and corrections during the final stage of publication. Interested readers are advised to consult the published version which can be found at:

http://www.sciencedirect.com/science/article/pii/S1096751602001124

doi: $\{10.1016 / \mathrm{S} 1096-7516(02) 00112-4\}$

Please refer this manuscript as:

Mäkitalo, K., Häkkinen, P., Leinonen, P., \& Järvelä, S. (2002). Mechanisms of common ground in case-based web discussions in teacher education. Internet and Higher Education, 5(3), 247-265. 


\section{Mechanisms of Common Ground in Case-Based Web-Discussions in Teacher Education}

Author-in-chief, contacts to:

Ph.D. Student Kati Mäkitalo

University of Jyväskylä/Institute for Educational Research

P.O Box 35, FIN-40014 UNIVERSITY OF JYVÄSKYLÄ, FINLAND

Tel.: +358 14260 3308; Fax: +358 14260 3201; Email: kati.makitalo@ktl.jyu.fi

Co-authors in this order:

Professor Päivi Häkkinen

University of Jyväskylä/Institute for Educational Research

P.O Box 35, FIN-40014 UNIVERSITY OF JYVÄSKYLÄ, FINLAND

Tel.: +358 14260 3231; Fax: +358 14260 3201; Email: phakkine@,cc.jyu.fi

Ph.D. student Piritta Leinonen

University of Oulu/Department of Educational Sciences and Teacher Education Research Unit for Educational Technology

P.O. Box 2000, FIN-90014 UNIVERSITY OF OULU, FINLAND

Tel.: +358 8553 3722; Fax +358 8553 3744; Email: pleinon@sun3.oulu.fi

Professor Sanna Järvelä

University of Oulu/Department of Educational Sciences and Teacher Education Research Unit for Educational Technology

P.O. Box 2000, FIN-90014 UNIVERSITY OF OULU, FINLAND

Tel.: +358 8553 3657; Fax +358 8553 3744; Email: sjarvela@sun3.oulu.fi 


\begin{abstract}
Previous studies suggest that before the participants in Web-based conferencing can reach deeper level interaction and learning, they have to gain an adequate level of common ground in terms of shared mutual understanding, knowledge, beliefs, assumptions, and presuppositions (Clark \& Schaefer, 1989; Dillenbourg, 1999). In this paper, the main purpose is to explore how participants establish and maintain common ground in order to reach deeper level interaction in case-based Web-discussions. The subjects in this study consisted of 68 pre-service teachers and 7 mentors from three universities, who participated in the Web-based conferencing course for eight weeks. The written discussion data were analyzed by means of a combination of quantitative and qualitative methods. The results suggest that in order to establish common ground it is essential that the participants, especially as fellow students, not only show evidence of their understandings through written feedback, but also provide support to their peers in their replies. Presenting questions also signals the participant's willingness to continue the discussion, which is essential for maintaining common ground.
\end{abstract}

\title{
Keywords
}

Common ground; Electronic discussion; Feedback; Grounding; Teacher education; Question; Web-based interaction

\section{Introduction}

According to several recent studies, social interaction supported by instructional technology can potentially lead to deeper understanding and new knowledge construction 
Mechanisms of Common Ground in Case-Based Web-Discussions in Teacher Education

(e.g. Crook, 1999; Koschmann, 1996). Computer Supported Collaborative Learning (CSCL) seems to be one of these promising innovations to improve teaching and learning with the advanced communication technology (Järvelä, Hakkarainen, Lipponen \& Lehtinen, 2000; Koschmann, 1996). CSCL could offer some supportive elements to collaborative learning, and moreover, it also enables researchers to investigate productive peer interactions (Crook, 1999; Dillenbourg, 1999).

There have been optimistic views that any possible network-based interaction can be educationally valuable. But also more pessimistic views about the quality of Web-based learning have been presented (Järvelä \& Häkkinen, 2002b; Roschelle \& Pea, 1999; Schlager, Fusco \& Schank, 2000; Stahl, 2002). There are several difficulties for using today's Web facilities as a medium for productive interaction. According to Roschelle and Pea (1999), interaction on the Web is highly text dependent, and partly for this reason they also regard asynchronous communication as being different from face-to-face communication.

There is a need to pay more attention to interactive processes on the Web. Some of the most important processes in human communication, like creation of mutual understanding or shared values and goals, are hard to reproduce in a Web-based environment (Järvelä \& Häkkinen, 2002a). The absence of visual information (e.g. missing facial expressions and non-verbal cues) increases the social distance between the participants (Järvelä \& Häkkinen, 2002a; Rovai, 2000). Therefore, it is important to consider how common ground could be created and maintained in virtual environments. In the present article an attempt is made to identify these elements of specific kind. 


\section{Common ground in Web-based interaction}

In the beginning of any interaction there will already be some degree of common ground between individuals sharing the same cultural background. But also the participants with a shared culture need to maintain and consolidate their common ground during the interaction itself in order to explore new aspects of their mutual knowledge. During the interactive process, which is called grounding, individuals build and maintain common ground by sharing mutual understanding, knowledge, beliefs, assumptions and pre-suppositions. (Clark \& Schaefer, 1989; Baker, Hansen, Joiner \& Traum, 1999) In collaborative activities it is essential to reach an adequate level of common ground (Dillenbourg, 1999).

According to Dillenbourg and Traum (1999), grounding can occur at the linguistic level as well as at the cognitive level. Furthermore, Veerman (2000) proposes that grounding can take place also at the level of understanding thematic information in relation to certain task and learning goals. For example, collaborative learning tasks should be designed so that the learning situations will offer possibilities for disagreement and misunderstanding as well (e.g. Häkkinen \& Arvaja, 1999).

\subsection{Establishing common ground}

In Web-based interaction, grounding means more than just the understanding of words. In order to communicate successfully, the two or more people involved need to be sensitive to each other and coordinate not only the content of what they are saying, but also the process of saying it, and seek evidence of how the other person is reacting to the message. Depending on their purposes, the participants adjust their grounding criteria to seek and provide some 
evidence that one's utterance is accepted. It is much easier for the participants to reach common ground in a face-to-face situation than in a Web-based environment. (Brennan, 1998) Web-based communication is mainly textual, which renders non-linguistic feedback to a minimum. It is not enough that participants just build common ground at the beginning of Web-based interaction. They also have to maintain common ground during the interactive processes to be able to deal with emerging new aspects of the common situation or task (Baker et al., 1999).

\subsection{Maintaining common ground}

Allwood, Nivre and Ahlsén (1991) describe four basic communicative functions essential for maintaining common ground. These factors form a four-level hierarchy. Clark and Schaefer (1987) show that participants cannot achieve any higher level of grounding if any of these levels fails. The four functions are contact, perception, understanding and attitudinal reaction.

\section{1) Contact}

Contact means that participants are willing and able to continue the interaction. It is essential for participants to feel that others are there to create a mutual sense of interaction (Cutler, 1995; Rovai, 2000). Participants can also feel isolated if they are not sure that others are reading the comments they post to the discussion forum, so cues about others being present and reading the messages are important (Rovai, 2000).

\section{2) Perception}

It means that participants are willing and able to observe the message in the Web-based environment. There can be hundreds of messages and it might be difficult to find the issues 
and topics which interest the most. Participants need to be active and make some efforts to find the messages.

\section{3) Understanding}

Understanding means that participants are willing and able to understand the message. Understanding refers to something more than just comprehending the words; the language that people use is loaded with, and thus mediates, historical and cultural meanings, and also situational factors can be interrelated to understanding (Säljö, 2001; See also Crook, 1994). In other words, the linguistic code is always somebody's interpretation for something (Säljö, 2001). An adequate level of mutual understanding about the content, situation, task, and goal is a prerequisite for effective interaction.

\section{4) Attitudinal reaction}

Participants are willing and able to react and respond to the message. In text-based interaction more attention need to be paid to the structure and content of responses so as to identify potential elements that keep discussions going on, for example, to examine how the participants express their attitudinal reaction in their replies.

All these elements - contact, perception, understanding, and attitudinal reaction - are linked together: an attitudinal reaction between persons cannot take place unless the message is first understood (or at least interpreted) which requires perception and contact (Baker et al., 1999; Clark \& Schaefer, 1987).

\subsection{Mechanisms of common ground in web-based conferences and the present study}

Figure 1 shows what kind of mechanisms of common ground might take place in Webbased conferences. The interrelated factors of course design and pedagogy include, for 
example, community size, environment and instruction (Rovai, 2000), which lay the foundations of the whole grounding process. For building common ground, the participants need to be aware of 1) the presence of others, 2) the process of diagnosis; participants have to think what they are saying but also how they are saying it, and 3) feedback; participants need to show their understanding in some form of feedback. Thus, the feedback can be a simple acknowledgment that the posting is received. (Baker et al., 1999) Even if the feedback consists of a simple acknowledgment that the message has been noticed and read, it is necessary for avoiding undue doubts of some participants that others are not reading the messages they post, and also for reaching mutual understanding (Brennan, 1998). Even when an adequate level of common ground is established, it does not guarantee that interaction will continue. In fact common ground needs to be maintained during the Web-based conferences by heeding the mechanisms of contact, perception, understanding and attitudinal reaction (Baker et al. 1999).

Insert Figure 1 about here

Figure 1. The mechanisms of common ground in Web-based conferences

As Figure 1 shows, there are many factors that can influence the interaction between participants. Within the frame of the present study the question arises whether the students who had not previously worked with each other, but were now brought together electronically for a joint effort, could be able to reach such interaction that would lead them to educationally relevant higher-level discussion and learning in Web-based environments? Building a 
Mechanisms of Common Ground in Case-Based Web-Discussions in Teacher Education

learning community, which would optimally support the joint study project, was one of the main goals in this particular teacher education course. The study described in this paper is part of a Finnish research project called SHAPE (Sharing and Making Perspectives in Virtual Interaction: Järvelä \& Häkkinen, 2002b; Saarenkunnas, Järvelä, Häkkinen, Kuure, Taalas \& Kunelius, 2000).

\section{Aim of this study}

The purpose of this study is to increase understanding about Web-based interaction by investigating the mechanisms of establishing and maintaining common ground in electronic discussion.

\section{Method}

\subsection{Participants}

The subjects of this study were limited to those students and mentors who actually wrote a posting or postings to the Web-based discussion forum. The subjects were pre-service teachers in the USA, University of Indiana $(n=35)$, and in Finland, Universities of Jyväskylä $(n=12)$ and Oulu $(n=21)$, in total 68 pre-service teacher students. As for the university teachers taking part as mentors, one came from the University of Indiana, two from the University of Jyväskylä and four from the University of Oulu. All the students had gained experience with field training in teacher education and had basic knowledge about computers and the Internet.

\subsection{Task}


The context of the study deals with the idea of case-based learning by using the Internet as a tool for pre-service teacher education. The students' learning task was to construct and maintain their personal case discussion and to summarize the discussion in the middle of the computer-supported learning course period and also at the end of it. For example, students could have described a problematic or pedagogically interesting situation encountered in their field training. In this project the students constructed case-based descriptions in areas such as 1) Authenticity and Context, 2) Fears in Educational Environment, 3) Technology, ICT and Education, 4) School, Home and Society, 5) Dealing with Difficult Situations and Delicate Matters, 6) Learning to Learn, 7) Becoming a Teacher, 8) Developing Learning Communities, 9) Creativity, and 10) Thinking, Understanding and Knowledge Construction. Students were requested to visit in an asynchronous Web-based learning environment called ProTo at least once a week during this eight-week project. Within this period the participants (students and mentors) produced a total of 449 messages.

\subsection{Data collection and analysis}

The written discussion data consisted of the participants' postings and contained 36 case discussions. In each discussion there were 4 to 26 postings, in total 386 postings. The case discussions that contained only one or two postings were left out from this set of data. A multi-phase analysis procedure was used in the following way:

\section{1) Charts}

At the beginning of the analysis for any given discussion a chart was made, which functioned as a research tool for exploring the path and content of discussions. At first the chart showed the posting location, information about on sender, the date when the posting was 
sent to the discussion forum and references to other postings. The charts were reformulated during further analyses (see Figures 2 and 3).

2) Identifying the levels of discussions

The method, which was partially applied here, is based on Järvelä's and Häkkinen's (2002a) model of analyzing the types of postings and the levels of discussions and perspective adoption. At the first stage the aim of the analysis was to examine the types of postings in order to organize the data. The postings were grouped into the following categories: Comment, Suggestion, Experience, New point/Question and Theory (Järvelä \& Häkkinen, 2002a). In their analysis Järvelä and Häkkinen (2002a) categorized individual postings to certain types and ranked these types with different values. For example, a theory-based posting was more valuable than a new point/question, an experience, a suggestion, or a comment etc. in this descending order.

Using previous analysis the discussions were grouped further into two different categories: progressive level and deeper level discussions. The progressive level discussions included plenty of comments, but also experiences and new points and questions. Theory-based postings did not occur in these discussions. The deeper level discussions, then again, contained high level postings such as theory-based postings and postings with reference to new point and question.

3) Defining mechanisms of common ground

This stage of analysis was data-driven. The data was looked through several times when the charts and the level of discussions were analyzed. At the final stage, the underlying theory of this study and the data were linked together. According to Brennan (1998), the grounding 
process requires that the partners are able to seek evidence of each other's understanding as well as provide evidence about their own understanding. A common form of feedback is a signal that the posting has been read and comprehended (Baker et al., 1999). Because feedback also gives evidence on how others are reacting to the sender's posting, this study sought to elucidate what kind of feedback the participants gave to each other during the Webbased conferencing course. As regards maintaining common ground in Web-based interaction, it was interesting to find out also how participants tried to keep the discussions going on. In this case the data diverted the researchers' attention on questions presented in the postings.

After each analysis stage the types of postings as well as the feedback and questions involved in particular postings were added to the charts. In this study we approached the written discussion data by using different methods including different stages. The content analysis involved many levels: the level of individual messages, interrelationships between two or more messages, and the level of the whole discussion. Finally, there is a comparison of the use of feedback and questions in different level discussions so as to find out possible specific mechanisms instrumental in shifting the interaction into a deeper level.

\section{Results}

\subsection{Levels of discussions}

The results show that 18 case discussions out of 36 were categorized to the progressive level (with a total of 179 postings) and the other half to the deeper level discussions (with 207 postings). The progressive level discussions involved plenty of comments, experience-based 
postings and some postings with new points or questions. Below there is an example of progressive level discussion:

Insert Figure 2 about here

Figure 2. An example of progressive level discussion; Case 6: "Teacher in trouble"

As Figure 2 shows, the case discussion of "Teacher in trouble" includes three comments, seven suggestions, four experience-based postings and three postings classified as new points or questions, in total 18 postings. In this case most postings were comments and suggestions and hence this discussion was categorized as a progressive level discussion. The following excerpt exemplifies postings typical of progressive level discussions. The posting headings are attached with explanations in brackets indicating e.g. the title, the sender, the date, and also the type of the posting.

Excerpt 1. Progressive level discussion

1. Teacher in trouble (title of the message) - NU (sender's fictitious initials) - 15:29 15-Mar2000 (time and date when the posting was sent to the forum)

What to do as a teacher/substitute teacher when you face a situation in which you haven't been before or haven't been prepared to deal with? For example, if something serious happens or a pupil gets into some kind of trouble.

We know a few occasions when a pupil has sewn through his/her finger with the sewing machine. The pupil's finger is stuck in the machine, the needle and the thread go through the finger, and he/she is hysterical. And the rest of the class is getting hysterical too. How to react?...

3. You're right! - KY - 12:49 26-Apr-2000 (suggestion, underlined)

I think you're absolutely right. ... Threfore, $I$ think that the school should really start to divide the students into smaller groups, because this way problems related to big groups sizes like disturbing the teacher, violence, etc. ... 
8. reply - TP - 16:00 29-Mar-2000 (comment, underlined)

Thanks for your comments. I think it is very important to make the preventive measures when possible. If earthquakes are expected on a certain area, they should naturally be taken into account in the construction of buildings....

9. Possible responses - DF(male student) - 08:25 27-Mar-2000_ (suggestion, underlined) You describe some interesting situations! Here are my responses:

1. There have been "a few" occasions when pupils have sewn their fingers up? Perhaps some preventative measures might be taken. Is there some kind of plastic guard that might be put on the machine to keep this from happening? Or maybe strong gloves for the students to wear?... Maybe there should be silence when sewing, no talking but maybe just music playing, to help them concentrate on the task at hand.

At the beginning of the discussion (see Excerpt 1, message 1) the case presenter introduced a problematic situation she had faced in her field training. As Excerpt 1 shows, she approached the problem from a very practical point of view. The replies to this case were mostly suggestions and comments on how the case presenter could deal with the situation. Generally, in the progressive level discussions the topics were rather practical, students were asking how they should go about and what they should think and do in particular teaching and learning situations. Therefore, the participants tended to share their opinions and suggestions only for practical issues and experiences in these discussions.

Deeper level discussions involved theory-based postings as well as new points or questions.

Insert Figure 3 about here

Figure 3. An example of deeper level discussion; Case 47: "How to improve creativity?" 
As Figure 3 shows, the discussion includes a lot of new point or question-based postings and also some theory-based postings, so this discussion was categorized into the deeper level.

Excerpt 2. Deeper level discussion

\section{How to improve creativity? - BU - 10:01 15-Mar-2000}

It is said that every people is someway creative. Of course there are many different ways how creativity appears. ...

How to improve school teaching so that pupils creativity can grow and develop?

What is your opinion about these:

There is a difference in creativity between girls and boys.

Pupils who have high grades in school are more creative than lower grade pupils.

\section{Creativity equals strategic thinking? - Mentor A - 13:32 15-Mar-2000 (theory-based)}

Really interesting questions! I think, however, that we should explore more the way we define creativity. If we look at the last statement you invite our opinions about, for example, I believe that it is true in the following way: If you say that creativity here means finding alternative and efficient ways to solve problems and shuttle your way through the educational system I am convinced that this is possible. In other words, awareness of your learning and learning strategies helps your to learn, but also to survive in the system. ...Whether this involves real learning, too, is different matter. Could this be this simple? Not really, but I have to continue my stream of consciousness writing later...

\section{7. good or bad? - MM - 21:53 28-Mar-2000 (theory-based)}

Susan, hello. It is really thoughtful that you take the stance of rejecting an attempt to dichotomize creativity along the gender line and that you hold a positive view that everyone has a certain degree of creativity. Your last point saying that some may be good at playing violins whereas others may be good at sports indeed echoed Dr. Howard Gardner's wellnotion of Multiple Intelligence. ...

10. Lots of interesting creativity questions... - DF - 08:11 27-Mar-2000 (question/new point) Here are my immediate responses to your questions:

1. Is creativity appreciated by teachers?....

I don't know what to say about the idea that girls or boys might be more creative. I kind of doubt there is really much difference, except for maybe some cultural influences in the content of the creative products (boys might write more stories, for instance, about stereotypically boyish interests such as war).

...Yes, an important challenge to teachers is to challenge, without dampening, their students' creativity.

Anyway, that is what I think. What about the rest of you? 
As the previous excerpt shows, this deeper level discussion involved a lot of theory-based and new point/question postings. The case presenter approached his problem-oriented issue at a more abstract level, which directed the interaction and proceeding of this discussion. The content of postings is important for carrying on the theme of discussion, but also the mechanisms for establishing and maintaining common ground effects the proceeding of discussion.

\subsection{Feedback in postings}

The next step was to find out what kind of feedback the participants used in their postings, and for this purpose the feedback was categorized to six different groups based on the analysis of discussion data. The feedback was categorized into the following groups: 1)

agreement/disagreement feedback, 2) personal feedback, 3) notifying feedback, 4) supporting feedback, 5) comparing feedback, and 6) paraphrasing feedback. Agreement or disagreement feedback obviously means that the respondent is agreeing or disagreeing on something with the sender.

"I still agree with you in that fostering learner needs is important and a goal which teachers should aim at." 47/3

"Hrm, I don't know. I'm not certain I fully agree." 3/3

Agreement and disagreement feedback focused on the topic unlike personal feedback, which was off-topic, focusing more on the sender's personality. In personal feedback, the message was addressed to the sender, including thank-you notes and also some emotional elements.

"Thank you for your opinion Susan." 1/5

"Hello John. You sound a little bit bitter." 1/12 
In notifying feedback the respondent was telling that the posting had been read, pointing out that the issue was interesting or that there was something needing sorting out or verification. Notifying feedback can also take shape as an explicit or implicit question, usually at the beginning of the posting, or when the recipients are repeating the sender's question or "talking" by themselves.

"So I think that comment seems weak overall." 47/15

"Here are my immediate responses to your questions." 47/10

"I would like to read more about your experiences about active teamwork at school." $26 / 8$

"So, Tina, the students in Finland learn more but like school less. Why is this?" 1/20

Notifying feedback was mainly focused on the topic, but it could also involve some functional elements like questions.

Supporting feedback was more positive in nature than the other types of feedback.

Supporting feedback means that the respondents expressed their support, because the issue was important or they wanted to give personal support to the addressee for some other reason.

"You raised an acute and important point of making science teaching more "concrete"." $1 / 13$

"I agree with Lena. You are not alone.---“" 1/25

In comparing feedback the respondents were sharing their own experiences or ideas and comparing them to those of the sender.

"The issue you describe---. I think this experience of mine is related to your case." $1 / 2$ "This reminds me of one unforgettable experience" $6 / 17$

Paraphrasing feedback means that the participants were explaining the sender's ideas/thoughts in their own way.

"It also happens that you may believe that you have understood---" $1 / 4$ 
"We assume that you mean critical reading and we see no reason why critical reading could not be done in a foreign language." $8 / 3$

Comparing and paraphrasing feedback showed actually something about the reactions of other participants. Perhaps previous postings had made them reflect on the topic and their own history (experiences) or they really tried to reach the sender's thoughts. Anyway, feedback of this kind gave an idea about what type of reactions the previous messages could provoke.

Usually such feedback is the first evidence telling something about the respondent's reaction and understanding. Table 1 below shows the types and amounts of feedback as well as the numbers of feedback users in progressive and deeper level discussions.

Table 1

The types and amounts of feedback in different level discussions, by participant's role Insert Table 1 here

Table 1 shows that out of the 386 postings 220 (57\%) included feedback of some sort. In deeper level discussions the participants used more feedback (124) than in progressive level discussions (96). Agreement/disagreement feedback was the most frequent type for both levels of discussions, although only three messages out of 76 included disagreement feedback. In terms of frequency, notifying feedback (45) came second, and the third most frequent type was personal feedback (40).

The findings suggest that when it comes to the use of feedback by students there were significant differences between different levels of discussions (Table 2), whereas no 
significant differences were found in the use of feedback by mentors or between students and mentors.

\section{Table 2}

The amount of feedback by students in progressive and deeper level discussions Insert Table 2 here

Students used more feedback in deeper level discussions than in progressive level discussions (Table 2). The difference in the amount of feedback by students for different levels of discussions is statistically significant $(p=0.094)$. Especially, standardized residuals are statistically significant in the use of supporting feedback by students. No significant differences were detected in mentors' feedback behavior for different levels of discussions, nor between students and mentors.

\subsection{Questions in postings}

The explicit and implicit questions were categorized into three different groups as follows (see Excerpt 3): Group A questions involved separate experiences, opinions and feelings in general, Group B questions were practically oriented and dealt with cause and effect or problem solving issues, where as Group C questions were related to negotiation of meanings, theory and relationships between different factors.

Excerpt 3. Examples of types of questions

\section{Group A}

"Pretty difficult situation or what do you think?" $17 / 10$

"Will I have to deal with a law suit because I send a letter home to parents who idolize their children? 17/6

\section{Group B}

"What is the matter in Finnish way of teaching science? Are the pupils more stupid here in dark and cold Finland in the middle of the polar bears than in other western countries? Or is it 
question about the way of teaching?. What is the way you are learning science? What would be the right way to teach?" $1 / 1$

"What do you think, how much education effects on our future?! How much parents know about children's needs?!?" 25/5

\section{Group C}

"Do you mean this by problem being accessible? What is your opinion about problem solving and social dimension in it? Is it worth of it if we try to solve the problem together or is it better way to try to solve the problem on one's own?" $1 / 9$

"I've always been curious to know that what is it that you study when you study technology education. Sounds as if it would among other things include some sort of engineering or mechanics as well." 10/2

"How to make science learning more meaningful? Is one way of doing this the integration of science teaching into authentic, real-life problems and project-enhanced settings? 1/13

The results show (see Table 3 below) that the postings of deeper level discussions accounted for about 58\% (114/195) of the total of explicit or implicit questions, while this percentage for progressive level discussions was about $42 \%(81 / 195)$.

Table 3

Questions presented in progressive and deeper level discussions by students and mentors Insert Table 3 about here.

There were significant differences between the types of questions in progressive level and deeper level discussions presented by students. Group C questions, which typically led the discussion into theory and negotiation, were more frequent in deeper level discussion than in progressive level discussions. The latter type discussions were characterized by more practical orientation and at this level the participants shared more opinions and experiences than in deeper level discussions.

\subsection{Mechanisms in Web-based discussion}


Excerpt 4 below exemplifies deeper level discussion between a student and a mentor. This excerpt shows how the participants used feedback and questions to establish and maintain common ground.

\section{Excerpt 4.}

\section{Science \& 'concrete teaching' - Mentor Carol - 15:50 15-Mar-2000}

"You raised an acute and important point of making science teaching more 'concrete'. Some further questions occurred into my mind. How to make science learning more meaningful? Is one way of doing this the integration of science teaching into authentic, real-life problems and project-enhanced settings? ..."

\section{About science and concrete teaching - Student John - 08:13 17-Mar-2000}

"You got the point, Carol! That is the way I think it should be. Especially connection to real life situation bring the problems much closer to pupils and so called "every day thinking"... ... So, what are teachers role in this system, example when it is question about project working? Do you have any suggestions?"

\section{5. teacher's role - Mentor Carol - 15:20 21-Mar-2000}

"I agree with you John about the importance of problem defining and framing. It is definitely one of the key points in this kind of problem-based approaches. Another related skill is also the ability to present the kind of questions that evoke elaborated explanations..."

In this excerpt the participants gave supporting feedback to each other, addressed the other person by name to maintain a personal contact, but also lent support to each other's thoughts and asked each other's opinion about the issue. An important thing was also that both participants showed in their replies that they accepted and appreciated the other one's responses (John message 14 and Carol 13 and 15). In other words, they also showed, e.g. by using questions, that they are eager to continue the interaction. John, the student and also the presenter of this case, showed he was able to challenge the mentor. So, we can assume that in this interaction process both the student and the mentor actually enjoyed the challenging 'mind storm' which motivated them to contribute to this particular discussion. 


\section{Discussion}

The results show that in terms of feedback and questions students used different interaction patterns at the different levels of discussion. In comparison to progressive level discussions, in deeper level discussions especially the peers gave more support directly by verbal feedback. This difference was statistically significant $(p=0.094<0.1)$. Mentors used the agreement/disagreement, notifying and comparing feedback more often in deeper level discussions than in progressive level discussions.

In progressive level discussions agreement feedback was more typical and that might have prevented proceeding to a deeper level. If participants fully agree on something it may soon be the end of discussion, because there is not much to discuss and feedback of this kind does not leave space for elaboration or negotiation about meanings (see Dillenbourg, 1999). It might also be so that the participants are satisfied with the mutual agreement and seemingly harmony and avoid risking it with new points or issues. Mentors used agreement feedback more often in deeper level discussions and it could be meant to serve rather as support. Agreement can be a sign that a common understanding is reached, but as Dillenbourg (1999) points out, in collaborative learning situations misunderstandings and corrections could offer the space for negotiation, which is a common mechanism of grounding. According to Brennan (1998), in Web-based discourse it is important that the participants provide evidence of their understanding, even when there is no place for misunderstandings. On the basis of these results we can assume that interaction is likely to be more fluent when the participants communicate their understanding, but also provide signals for their willingness to continue the interaction with each other. 
In deeper level discussions supporting feedback was more frequent. The results suggest that positive feedback encourages people to participate in discussion and thereby engage in the group actively contributing to the Web-based learning environment (see Hara, Bonk \& Angeli, 2000). In light of these results it seems that supporting feedback has a positive impact on Web-based interaction processes, which is hardly a surprise. According to McMillan (1996), the members of community need support, and they also offer the support in times of need, and feedback of this kind lays on the trust of community. Wegerif (1998) suggests that creating a sympathetic sense of community is a necessary first step for collaborative learning.

The results show that a typical feature of deeper level discussions was constructive communication between the participants. These results imply that in order to establish and maintain common ground it is important to use the kind of feedback and questions that supports constructive Web-based interaction. According to Brennan (1998), in order to reach a deeper level discussion, each participant's need to receive feedback should be recognized not only when there is a problem, but also when there are no evident problems. This is in line with our finding that in deeper level discussions feedback was used more often than in progressive level discussions, giving thus the participants a better understanding of each other's views. Based on the results of this study, it could be possible to specifically instruct the on-line learners to provide feedback to each other so as to reach common ground more effectively in the Web-based community (see Rovai, 2000).

The findings also suggest that participants involved in deeper level interaction also show positive attitudes toward responding the questions concerned. Questions presented in deeper level discussions included theory-based considerations, relationships between different factors 
and negotiation more typically than at the progressive level. In other words, the question patterns were intellectually more challenging in deeper level discussions than in progressive level discussions.

Clark and Schaefer (1989) have noted contributions take many forms, in some instances discussion arises from single words or phrases, while in other occasions it takes clauses, full sentences, or whole turns. Further studies in this field should focus rather on full postings and the proceeding of whole discussions than on any specific words or phrases. As the results show it is important that participants include in their replies both social and cognitive cues (feedback and questions) to encourage the fellow students to participate in the discussion. For Web-based learning discussions, in particular, the need for such interaction is evident. Thus, the analysis methods used in this study call for further elaboration, because of the focus given to single sentences. In fact, exploration of mere textual data does not necessarily capture the whole process of grounding and related mechanisms of common ground in Web-based conferences. This would require consideration of the wider context of social interaction and learning. Participants who share the same classroom during a Web-based conference are also likely to build and maintain common ground face-to-face, and not just within the computersupported framework (Crook, 1999). Further research is needed to cover also these areas of interaction in connection with Web-based activities.

\section{Acknowledgements}

This research was supported by Grant No. 37189 from the Academy of Finland. 
Mechanisms of Common Ground in Case-Based Web-Discussions in Teacher Education

\section{References}

Allwood, J., Nivre, J. \& Ahlsén, E. (1991). On the semantics and pragmatics of linguistic feedback (Gothenburg Papers in Theoretical Linguistics No. 64). Sweden: University of Gothenburg, Department of Linguistics.

Baker, M., Hansen, T., Joiner, R. \& Traum, D. (1999). The role of grounding in collaborative learning tasks. In: P. Dillenbourg (Ed.), Collaborative learning. Cognitive and computational approaches (pp. 31-63). Advances in Learning and Instruction Series. Amsterdam: Pergamon.

Brennan, S. E. (1998). The grounding problem in conversations with and through computers. In: S. R. Fussell \& R. J. Kreuz (Eds.), Social and cognitive approaches to interpersonal communication (pp. 201-225). Mahwal, NJ: Erlbaum.

Clark, H. H. \& Schaefer, F. S. (1987). Collaborating on contributions to conversation. Language and Cognitive Processes, 2, 1-23.

Clark, H. H. \& Schaefer, F. S. (1989). Contributing to discourse. Cognitive Science, 13, 259294.

Crook, C. (1994). Computers and the collaborative experience of learning. London: Routledge.

Crook, C. (1999). Computers in the community of classrooms. In: K. Littleton \& P. Light (Eds.), Learning with computers. Analysing productive interaction (pp. 102-117). London: Routledge.

Cutler, R. H. (1995). Distributed presence and community in cyberspace. Interpersonal Communication and Technology: A Journal for the $21^{\text {st }}$ Century, 3 (2), 12-32. 
Mechanisms of Common Ground in Case-Based Web-Discussions in Teacher Education

Dillenbourg, P. (1999). Introduction: What do you mean by “collaborative learning”? In: P. Dillenbourg (Ed.) Collaborative learning. Cognitive and computational approaches (pp. 1-19). Advances in Learning and Instruction Series. Amsterdam: Pergamon. Dillenbourg, P. \& Traum, D. (1999). Does a shared screen make a shared solution? In: C. Hoadly \& J. Roschelle (Eds.), Proceedings of the third conference on computer supported collaborative learning (pp. 127-135). California: Stanford University.

Hara, N., Bonk, C. J. \& Angeli, C. (2000). Content analysis of online discussion in an applied educational psychology course. Instructional Science, 28, 115-152.

Häkkinen, P. \& Arvaja, M. (1999). Kollaboratiivinen oppiminen teknologiaympäristöissä. [Collaborative learning in technology-supported environments]. In: A. Eteläpelto \& P. Tynjälä (Eds.), Oppiminen ja asiantuntijuus. Työelämän ja koulutuksen näkökulmia. [Learning and expertise. Aspects of work and education] (pp. 206-221). Porvoo: WSOY.

Järvelä, S., Hakkarainen, K., Lipponen, L. \& Lehtinen, E. (2000). Creating computer supported collaborative learning in Finnish schools: Research perspectives on sociocognitive effects. Journal of Continuing Engineering Education and Life-Long Learning, 10 (2), 1-10.

Järvelä, S. \& Häkkinen, P. (2002a, in press). The levels of Web-based discussions - using perspective-taking theory as an analysis tool. In: H. Van Oostendorp (Ed.), Cognition in a digital world. Lawrence Erlbaum. 
Mechanisms of Common Ground in Case-Based Web-Discussions in Teacher Education

Järvelä, S. \& Häkkinen, P. (2002b, in press). Web-based cases in teaching and learning - the quality of discussion and a stage of perspective taking in asynchronous communication. Interactive Learning Environments, 10 (1), 1-22.

Koschmann, T. (1996). Paradigm shifts and instructional technology: An introduction. In: T. D. Koschmann (Ed.), CSCL: Theory and practice of an emerging paradigm (pp. 1-24). Hillsdale, NJ: Lawrence Erlbaum.

McMillan, D. W. (1996). Sense of community. Journal of Community Psychology, 24 (4), $315-325$.

Roschelle, J. \& Pea, R. (1999). Trajectories from today's WWW to a powerful educational infrastructure. Educational Researcher, 28 (5), 22-25.

Rovai, A. P. (2000). Building and sustaining community in asynchronous learning networks. The Internet and Higher Education, 3 (4), 285-297.

Saarenkunnas, M., Järvelä, S., Häkkinen, P., Kuure, L., Taalas, P. \& Kunelius, E. (2000). NINTER - Networked Interaction: Theory-based cases in teaching and learning. Learning Environments Research, 3, 35-50.

Schlager, M. S., Fusco, J. \& Schank, P. (2000). Evolution of an on-line education community of practice. In: K. A. Renniger \& W. Shumar (Eds.), Building virtual communities: Learning and change in cyberspace. NY: Cambridge University Press.

Stahl, G. (2002). Contributions to a theoretical framework of CSCL. In: G. Stahl (Ed.), Proceedings of computer supported for collaborative learning: Foundations for a CSCL community (CSCL 2002). (pp. 62-71) Hillsdale, NJ: Lawrence Erlbaum. Available at http://www.cscl2002.org/docs/CSCL2002_Proceedings.pdf. Retrieved January 3, 2002. 
Mechanisms of Common Ground in Case-Based Web-Discussions in Teacher Education

Säljö, R. (2001). Oppimiskäytännöt. Sosiokulttuurinen näkökulma. [Practices of learning. Socio-cultural aspect]. Helsinki: WSOY.

Veerman, A. (2000). Computer-supported collaborative learning through argumentation. Utrecht: Interuniversity Center for Educational Research.

Wegerif, R. (1998). The Social dimension of asynchronous learning networks. Journal of Asynchronous Learning Networks, 2 (1), 34-49. 
Mechanisms of Common Ground in Case-Based Web-Discussions in Teacher Education

Table 1. The types and amounts of feedback in different level discussions, by participant's role

\begin{tabular}{|c|c|c|c|c|c|}
\hline \multirow{2}{*}{$\begin{array}{l}\text { Level of Discussion } \\
\text { Type of Feedback }\end{array}$} & \multicolumn{2}{|c|}{$\begin{array}{l}\text { Progressive Level } \\
\text { Discussions }\end{array}$} & \multicolumn{2}{|c|}{$\begin{array}{l}\text { Deeper Level } \\
\text { Discussions }\end{array}$} & \multirow{2}{*}{$\begin{array}{l}\text { The Total } \\
\text { Amount } \\
\text { of } \\
\text { Feedback }\end{array}$} \\
\hline & Students & Mentors & Students & Mentors & \\
\hline 1. Agreement/Disagr. & 39 & 1 & 29 & 7 & 76 \\
\hline Feedback & $45.9 \%$ & $9.0 \%$ & $30.9 \%$ & $23.3 \%$ & $35.5 \%$ \\
\hline 2. Personal & 17 & 2 & 16 & 5 & 40 \\
\hline Feedback & $20.0 \%$ & $18.2 \%$ & $17.0 \%$ & $16.7 \%$ & $18.0 \%$ \\
\hline 3. Notifying & 13 & 3 & 21 & 8 & 45 \\
\hline Feedback & $15.3 \%$ & $27.3 \%$ & $22.3 \%$ & $26.7 \%$ & $20.0 \%$ \\
\hline 4. Supporting & 4 & 2 & 15 & 3 & 24 \\
\hline Feedback & $4.7 \%$ & $18.2 \%$ & $16.0 \%$ & $10.0 \%$ & $10.9 \%$ \\
\hline 5. Comparing & 7 & - & 7 & 5 & 19 \\
\hline Feedback & $8.2 \%$ & - & $7.4 \%$ & $16.7 \%$ & $8.6 \%$ \\
\hline 6. Paraphrasing & 5 & 3 & 6 & 2 & 16 \\
\hline Feedback & $5.9 \%$ & $27.3 \%$ & $6.4 \%$ & $6.6 \%$ & $7.0 \%$ \\
\hline Total & $\begin{array}{c}85 \\
100 \%\end{array}$ & $\begin{array}{c}11 \\
100 \%\end{array}$ & $\begin{array}{c}94 \\
100 \%\end{array}$ & $\begin{array}{c}30 \\
100 \%\end{array}$ & $\begin{array}{c}220 \\
100 \%\end{array}$ \\
\hline
\end{tabular}


Mechanisms of Common Ground in Case-Based Web-Discussions in Teacher Education

Table 2. The amount of feedback by students in progressive and deeper level discussions

\begin{tabular}{lccc}
\hline $\begin{array}{c}\text { Level of } \\
\text { Discussion }\end{array}$ & $\begin{array}{c}\text { Progressive } \\
\text { Level } \\
\text { Discussions }\end{array}$ & $\begin{array}{c}\text { Deeper } \\
\text { Level } \\
\text { Discussions }\end{array}$ & Total \\
\hline 1. Agreement/Disagr. & 39 & 29 & $\mathbf{6 8}$ \\
Feedback & $45.9 \%$ & $30.9 \%$ & $\mathbf{3 8 . 0 \%}$ \\
2. Personal Feedback & 17 & 16 & $\mathbf{3 3}$ \\
& $20.0 \%$ & $17.0 \%$ & $\mathbf{1 8 . 4 \%}$ \\
3. Notifying Feedback & 13 & 21 & $\mathbf{3 4}$ \\
4. Supporting Feedback*) & $15.3 \%$ & $22.3 \%$ & $\mathbf{1 9 . 0} \%$ \\
& 4 & 15 & $\mathbf{1 9}$ \\
5. Comparing Feedback & $4.7 \%$ & $16.0 \%$ & $\mathbf{1 0 . 6 \%}$ \\
& 7 & 7 & $\mathbf{1 4}$ \\
6. Paraphrasing Feedback & $8.2 \%$ & $7.4 \%$ & $\mathbf{7 . 8 \%}$ \\
& 5 & 6 & $\mathbf{1 1}$ \\
Total & $5.9 \%$ & $6.4 \%$ & $\mathbf{6 . 1 \%}$ \\
\hline
\end{tabular}

*)Pearson Chi-Square Value $=9.414, \mathrm{df}=5, \mathrm{p}=0.094<0.1$

Standardized residuals are statistically significant. 
Mechanisms of Common Ground in Case-Based Web-Discussions in Teacher Education

Table 3. Questions presented in progressive and deeper level discussions by students and mentors

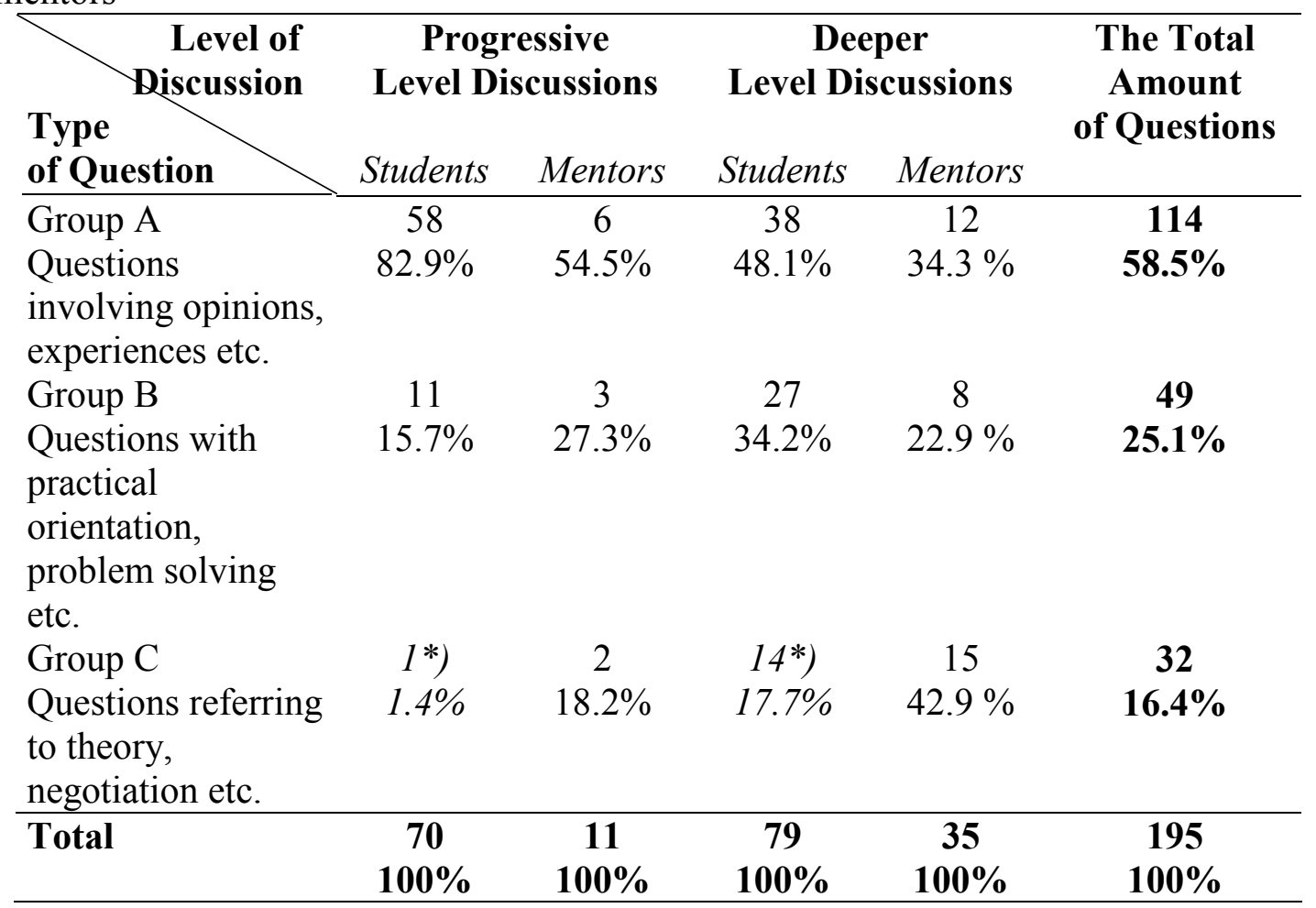

*) Pearson Chi-Square Value $=21.706, \mathrm{df}=2, \mathrm{p}=0.000$

Standardized residuals are statistically significant. 


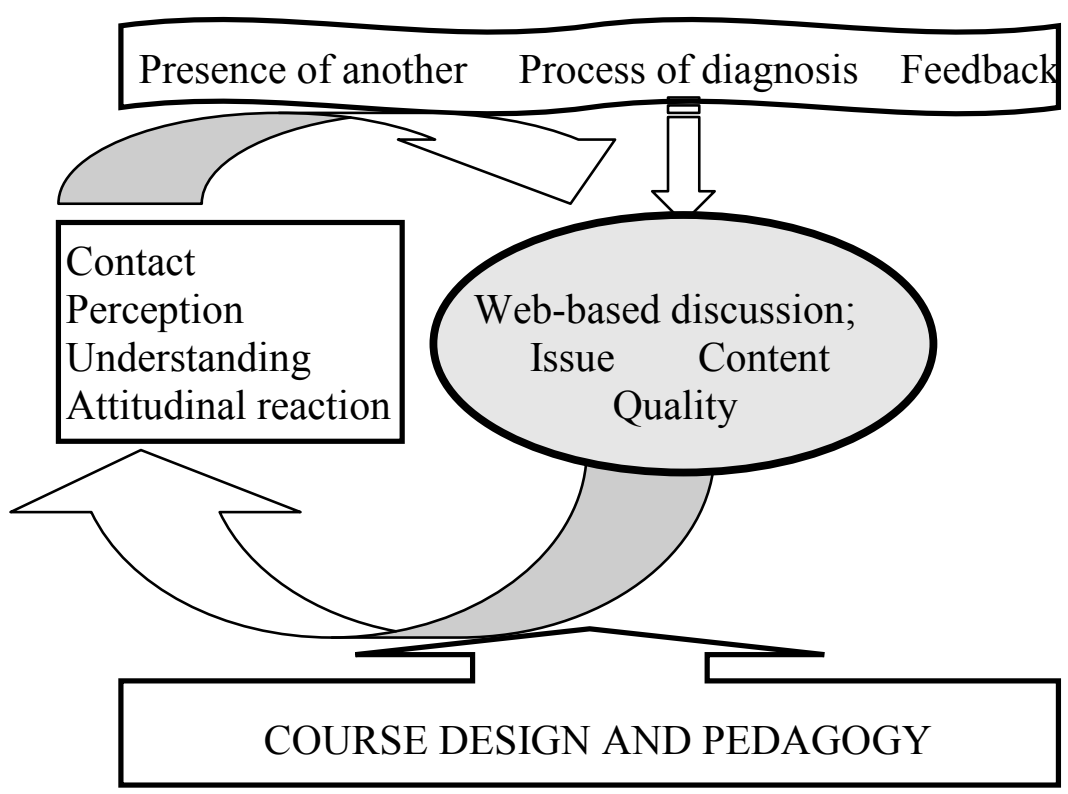

Figure 1. The mechanisms of common ground in Web-based conferences 


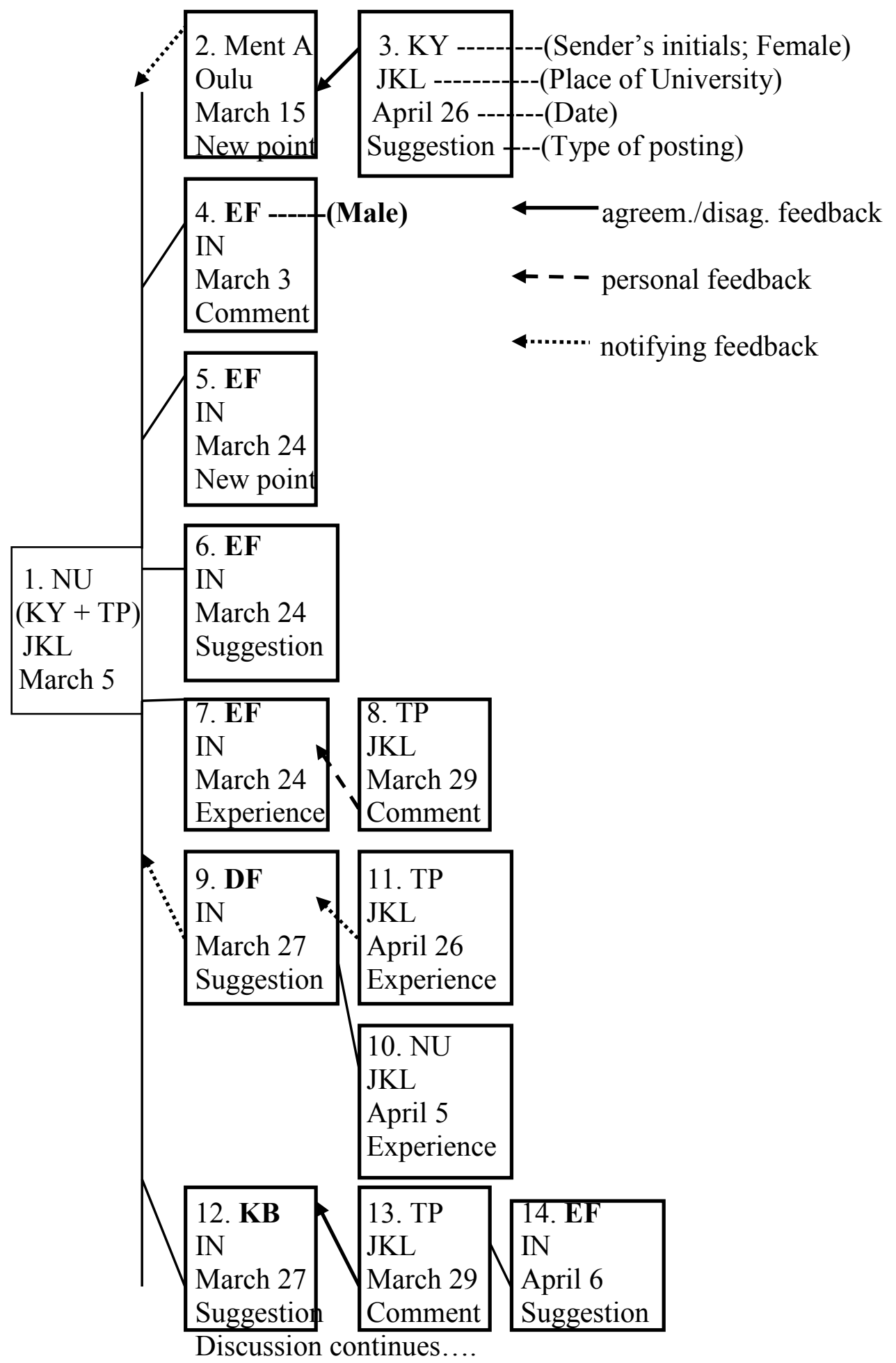

Figure 2. An example of progressive level discussion; Case 6: "Teacher in trouble" 


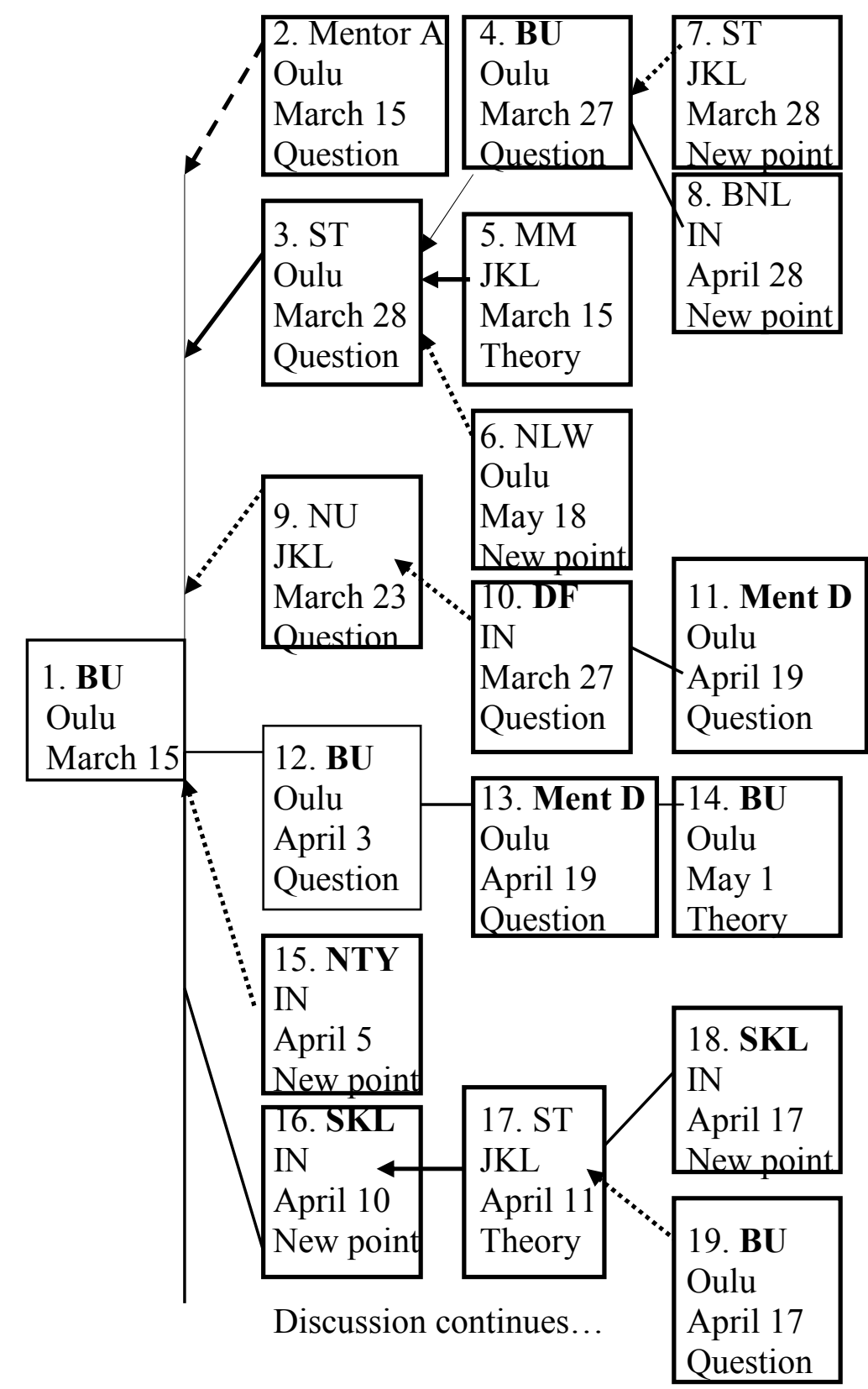

$\longleftarrow$ Agreement/Disagr. feedback $\leftarrow$ - . Supporting feedback
4...... Notifying feedback

$4 \quad$ Comparing feedback

Figure 3. An example of deeper level discussion; Case 47: "How to improve creativity?" 